\title{
Nano-particles in heterogeneous catalysis
}

Alfons M. Molenbroek*, Stig Helveg, Henrik Topsøe, and Bjerne S. Clausen

Haldor Topsфe A/S, Nymøllevej 55, DK-2800 Kgs. Lyngby, Denmark

Fax: (+45) 45272999

*Corresponding Author: E-mail: am@topsoe.dk

Keywords: Heterogeneous catalysis; Nano-particles; in situ characterization techniques

\section{Scope: Operando spectroscopy: from proof of concept to industrial application}

\begin{abstract}
The introduction of in situ techniques has had a vast impact on research and development in the area of heterogeneous catalysis as emphasized in many reviews and monographs ${ }^{[1-7]}$. Recently, the number of in situ techniques that can give information at the atomic scale has increased significantly and new possibilities exist for making the measurements under industrially relevant conditions. In order to fully exploit the results from the in situ and operando studies, it has also become increasingly gainful to combine the experimental studies with theoretical methodologies based on, for example, Density Functional Theory (DFT). This has allowed one to extract more detailed atomic-scale information from the measurements and it has also allowed the establishment of detailed structure-activity relationships. Furthermore, the interplay between in situ techniques and theory has helped bridging the pressure gap such that in situ information obtained at conditions far from industrial ones may be used in a more relevant manner. Here, we will illustrate how microscopy-, spectroscopy- and X-raybased techniques in combination with experimental and theoretical surface science methods can aid industrial catalyst developments. We will do this by presenting examples of our current understanding and latest developments in the areas of heterogeneous nano-particle catalysts for methanol synthesis, steam reforming and hydrotreating.
\end{abstract}




\section{Introduction}

Solid particles with a size of below approximately $20 \mathrm{~nm}$ have a large fraction of their atoms present at the surface. The characteristics of the surface atoms are significantly different from atoms in deeper layers, as e.g. bond distances, geometries, and bonding energies are altered by the reduced local coordination at the surface. Also the atomic composition at the surface might be different than that in the bulk of the particle.

In heterogeneous catalysis, the special properties of the surface atoms facilitate conversion of reactants into products at active surface sites. The properties of the active surface sites depend among others on the type and number of the surrounding atoms at the surface, the supporting material and the presence of reactants and products. A detailed description of the nano-particle structure and reactivity is therefore of utmost importance in order to establish rational catalyst design strategies.

Although nano-particles may be synthesized with predefined shapes and hence surface sites, there is no guarantee that the as-synthesized nano-particles remain stable when subjected to the reaction conditions. The realization that the catalyst surface structures and therefore catalytic properties depend on the reaction conditions has spurred a tremendous interest in obtaining atomic-scale information about the structural and chemical state of catalysts during exposure to reaction conditions. The development of new experimental techniques combined with miniaturized reactors for the study of supported nano-particle catalysts under in situ and operando conditions has resulted in a significant improvement of the fundamental understanding of the influence of particle size, particle shape, alloying, and aggregation on the activity, selectivity, and deactivation of the catalysts. The main drivers for the improved understanding are new experimental advancements in the fields of e.g. electron microscopy, X-ray and, synchrotron-based techniques, and optical spectroscopy in combination with activity measurements by e.g. mass spectrometry. Experiments under operando conditions require the combined simultaneous measurement of catalytic activity/selectivity with a structural probe under realistic reaction conditions and are therefore relatively seldom reported. The majority of the catalytically relevant experiments is performed under less stringent in situ conditions, where a structural probe is used to give information on a catalyst during e.g. activation or operation. The combination of such in situ techniques providing atomic-scale insight of the individual nano-particles and spatially-averaged 
structural and chemical information has shown to be extremely powerful for probing the structure-function relationships of supported nano-particle catalysts. Also, the applications of Scanning Probe Microscopy ${ }^{[8]}$ and theoretical techniques, e.g. DFT [9], have contributed significantly to the atomic-scale insight in structure, active sites, transition states and reactivity at catalyst surfaces, especially when combined with in situ experimentation.

In this article, an overview is given of some of the latest findings on characterization of active surface sites, reactant-induced shape changes and (de)activation, and the relationship between theory and experiments for selected nano-particle catalysts in the areas of methanol synthesis, steam reforming and hydrotreating.

\section{Supported Cu catalysts}

In the methanol synthesis process, a synthesis gas consisting of a mixture of hydrogen, carbon monoxide and carbon dioxide is converted catalytically to methanol and water at gas pressures of $10-73$ bar and temperatures in the range of $200-250^{\circ} \mathrm{C}$. The technical methanol synthesis catalysts consist of $\mathrm{Cu}$ nano-particles supported on a high-surface area $\mathrm{ZnO}-\mathrm{Al}_{2} \mathrm{O}_{3}$ carrier. It is generally accepted that $\mathrm{Cu}$ works as a methanol synthesis catalyst and that the activity increases significantly for $\mathrm{Cu}$ supported by $\mathrm{ZnO}$, which on its own has negligible activity in the process. The origin of the metal-support synergy in the $\mathrm{Cu} / \mathrm{ZnO}$ system has been much debated ${ }^{[10]}$. For instance, it has been proposed that the synergy includes support-induced strain in $\mathrm{Cu}{ }^{[11,12]}, \mathrm{Zn}$-species migration onto $\mathrm{Cu}$ ${ }^{[13]}$, a $\mathrm{Cu}-\mathrm{Zn}$ alloy formation ${ }^{[14-16]}$ or a gas-dependent morphology of $\mathrm{Cu}$ on $\mathrm{ZnO}{ }^{[17,18]}$. The methanol synthesis reaction has become a prototype reaction for studying complex metal-support interactions and the application of in situ techniques has played an important role for establishing an understanding of the methanol synthesis process.

The catalyst precursor consists of a substitutional solid solution of $\mathrm{Cu}$ in $\mathrm{ZnO}$, as determined by resonant X-ray diffraction ${ }^{[19]}$. Separate $\mathrm{CuO}$ particles are also present in the precursor for $\mathrm{Cu}$ loadings above the solubility limit of $\mathrm{Cu}$ in $\mathrm{ZnO}$. During activation (reduction) of the precursor, $\mathrm{Cu}$ atoms leave the solid solution or the oxidic state to form metallic $\mathrm{Cu}$ nano-crystallites with an average size of a few $\mathrm{nm}$. The size distribution of the $\mathrm{Cu}$ and $\mathrm{ZnO}$ particles was obtained by in situ anomalous SmallAngle X-ray Scattering (SAXS) by tuning the incoming X-ray energy close to the $\mathrm{Cu}$ 
and $\mathrm{Zn}$ absorption edges, respectively. By employing a specially developed reaction cell ${ }^{[20]}$, the results suggested broad bimodal distributions of $\mathrm{Cu}$ and $\mathrm{ZnO}$ particles ${ }^{[19]}$. Upon reduction of the precursor, the $\mathrm{Cu}$ oxidation state changes from $\mathrm{Cu}^{2+}, \mathrm{via} \mathrm{Cu}^{+}$to metallic $\mathrm{Cu}$, as determined by in situ Quick Extended X-ray Absorption Fine Structure (QEXAFS) spectroscopy ${ }^{[21]}$.

Following activation, the $\mathrm{Cu}$ catalyst is exposed to syngas and the concentration of methanol and water increases through the reactor. Consequently, the oxidation potential of the gas phase changes and the in situ results reveal, as discussed below, that this affects the shape of the active $\mathrm{Cu}$ particles dramatically. In situ Extended X-ray Absorption Fine Structure (EXAFS) studies under industrial $\left(220^{\circ} \mathrm{C}, 48\right.$ bar) conditions have shown that metallic $\mathrm{Cu}$ is the active phase under methanol synthesis conditions ${ }^{[22]}$. Later, it was found that in time-resolved XAFS/X-ray Diffraction (XRD) studies, combined with on-line mass spectrometry, the apparent $\mathrm{Cu}-\mathrm{Cu}$ coordination number of a $\mathrm{Cu} / \mathrm{ZnO}$ catalyst changes reversibly with changes in the oxidation potential of the synthesis gas mixture ${ }^{[17,18]}$ (Figure 1). Due to the larger anharmonicity of the vibration of surface atoms compared to bulk atoms, the relation between the coordination number and the particle size and morphology is not straightforward but was described well in a combined XAFS/XRD/Molecular Dynamics study ${ }^{[23]}$. The gas-dependent $\mathrm{Cu}-\mathrm{Cu}$ coordination number changes were initially attributed to dynamic morphology changes of the $\mathrm{Cu}$ nano-particles involving a wetting/non-wetting of the $\mathrm{ZnO}$ support by $\mathrm{Cu}$ depending on the oxidation potential of the gas phase ${ }^{[24]}$ (Figure 1). It was proposed that the dynamic shape changes are related to variations in the oxidation potential that may change the oxygen content in the $\mathrm{ZnO}$ surface and thereby the interface energy ${ }^{[24]}$. A low oxygen content will give a strong decrease in the $\mathrm{Cu} / \mathrm{ZnOx}$ interface energy because of a partial reduction of the $\mathrm{ZnO}$ surface layer. On the other hand, at large oxygen contents the $\mathrm{ZnO}$ surface is completely oxidized with a low concentration of oxygen vacancies so the interface energy is correspondingly high. For non-reducible supports, such as silica and alumina, similar gas-dependent shape changes of the $\mathrm{Cu}$ nano-particles were not observed and this is attributed to a higher vacancy formation energy in the surface of these supports so the interface energy is only affected slightly by the a change in the oxidation potential of the gas phase. 
The implication of the gas-dependent nano-particle morphology is a change in the active surface area and the distribution of exposed surface sites, which was incorporated in a "dynamic micro-kinetic model" [24] for the methanol synthesis, based on surface science input. Also for kinetic modeling of the water-gas shift reaction, the dynamic shape changes have important consequences ${ }^{[25]}$. The kinetic model for the methanol synthesis reaction includes the change in the number of active sites and the exposed $\mathrm{Cu}$ facets as a function of reaction conditions and is able to explain methanol synthesis rates under industrial conditions more satisfactorily as compared to a model including a static morphology of the $\mathrm{Cu}$ nano-crystals (Figure 2). Furthermore, the dynamic nano-particle morphology also provides a consistent explanation for a transient peak production of methanol that can be observed after the change-over of exposing the $\mathrm{Cu} / \mathrm{ZnO}$ catalyst from activation conditions to synthesis gas conditions. ${ }^{[26,27]}$.

Detailed insight into these adsorbate-induced changes in surface and interface energies became possible by the introduction of in situ capabilities in high-resolution transmission electron microscopy (TEM); the so-called environmental TEM (ETEM) [28]. The direct atomic-resolved images of individual nano-crystals help to identify the driving force for the shape transformations which are in accord with the EXAFS results (Figure 3). The ETEM results, however, provide important additional information: Based on the lattice-resolved images, it is possible to establish Wulff constructions for the nano-crystals and a quantitative determination of the changes in the surface and the interface free energy in the various gas environments. This information allows a full 3D shape of the supported copper nano-crystals to be made, which in turn may provide important information regarding the concentration of the different types of surface sites (low-index planes, corners, steps, etc.) under reaction conditions. Insight at this level has a significant impact on the understanding of the catalysis since it allows the gasdependent morphology changes to be incorporated into a "dynamic micro-kinetic model" of the catalytic reaction. Previous descriptions of the catalysis had to rely on assumptions regarding the nature of the exposed surfaces. It is important to mention that the atomic-resolved images were obtained in situ during exposure to reactive gas environments at relevant temperatures but at modest gas pressures of up to ca. 10 mbar. Recently, similar images were obtained of $\mathrm{Cu}$ supported on $\mathrm{ZnO}$ during exposure to reducing gas conditions at 1 bar ${ }^{[29]}$. The ability to image catalysts during exposure to relevant reaction conditions is a significant step forward, since it allows direct in situ 
observations of individual nano-particles rather than the results from space-averaged in situ techniques. Although the conditions in the experimental setups are not exactly the same as encountered in industry, we can use this new insight and the theoretical understanding to predict what changes may occur at the high pressures employed in technical applications.

More insight into the gas-dependent metal-support interactions in the $\mathrm{Cu} / \mathrm{ZnO}$ catalysts was obtained by combining the ETEM results with in situ electron energy loss measurements ${ }^{[30]}$. As the reduction potential in the gas phase is increased, the wetting of the $\mathrm{ZnO}$ by copper is accompanied by a slight intensity increase in the energy loss near edge structure (ELNES) at the $\mathrm{Cu} L_{3}$ ionization edge. By comparison of these observations with spectral simulations, the increase in the ELNES intensity is interpreted as a $\mathrm{Cu}-\mathrm{Zn}$ alloy formation at the $\mathrm{Cu}-\mathrm{ZnO}$ interface or at the copper surface. Consistent with this, in situ infrared spectroscopy studies indicated that the formation of a $\mathrm{Cu}-\mathrm{Zn}$ surface-alloy can occur at high temperatures ${ }^{[14,31]}$ and that this phenomenon depends strongly on the reduction potential of the surrounding gas ${ }^{[10]}$. These findings suggest that several structural effects may contribute simultaneously depending possibly on the nanoparticle preparation and methanol synthesis conditions. A systematic study of the relative importance of the alloy ${ }^{[15,16]}$ and strain effects ${ }^{[11,32]}$ compared to the gas-induced morphology $[17,18,24]$ is required in order to evaluate which of these phenomena plays the dominating role on the methanol synthesis activity. It is clear that with the variety of new in situ and operando techniques available, one will be able to unravel such complex phenomena.

\section{Supported Ni catalysts}

In the steam-reforming process, methane or other hydrocarbons are dissociated at the surface of supported Ni nano-clusters and reacted with steam to form hydrogen and carbon monoxide ${ }^{[33]}$. Steam reforming is the main industrial process that is used for the production of hydrogen and synthesis gas. The process runs at high pressure (up to 40 bar), high temperatures (between $450-950^{\circ} \mathrm{C}$ ) and in order to make the process economically favorable, a low carbon-to-oxygen ratio is preferred. As a result of these severe reaction conditions, however, deactivation processes may be induced resulting in an ensemble of less active Ni nano-clusters. 
To establish a detailed understanding of the catalyst deactivation phenomena, a thorough understanding of gas-surface interaction on the working catalyst is needed. Although the kinetics of nickel-based steam-reforming catalysts has been subject to many studies, as reviewed in ${ }^{[3,34]}$ it was only recently that an atomic-scale picture for the complete methane steam-reforming reaction was established by combining theoretical and experimental studies ${ }^{[35-37]}$. It turned out that at least two kinds of active sites on surfaces of the supported Ni nano-particles are necessary to describe the steam reforming process: high active sites associated with defect (step) sites at the Ni surface and less active sites associated with the close-packed facets (Figure 4). The understanding of the gas-surface interactions also allowed a detailed picture of significant catalyst deactivation phenomena, such as catalytic carbon deposition and nano-particle sintering, to be developed.

Under sufficiently low carbon-to-oxygen ratios, carbon may be deposited in the $\mathrm{Ni}$ based steam-reforming catalyst in the form of encapsulating carbon, pyrolytic carbon and carbon nanofibers. The carbon deposition is particular detrimental for the catalyst pellets when it happens in the form of graphitic fibers or whiskers, because these filaments eventually will break-down the pellet structure, pulverize the catalyst and result in a severe pressure drop over the reactor. Detailed insight into the catalytic growth of the graphitic fibers was obtained by using ETEM ${ }^{[37-41]}$. In fact, in their pioneering applications of ETEM in the 1970ies, Baker et al. studied growth of carbon nanofibers by catalytic acetylene decomposition ${ }^{[38,42]}$. However, as the microscope resolution was limited to $2-3 \mathrm{~nm}$, the detailed structure and dynamics of the exposed catalyst surfaces was not possible to resolve and only with more recent advances in microscopy it has become possible to achieve such information at the atomic-scale ${ }^{[37,39 \text {, }}$ 40].

By acquiring time-resolved image series of Ni nano-crystals in situ during growth, Ni nano-clusters were observed to undergo a reaction-induced reshaping that acts as a template for the alignment of graphene layers into multi-walled carbon nano-fiber structures ${ }^{[37,40]}$. Figure 5 shows an image series for a Ni nano-crystal with a diameter of ca. $6 \mathrm{~nm}$. The initial compact equilibrium shape of the Ni nano-crystal is seen to transform into a highly elongated shape that at a high aspect ratio abruptly contracts into a spherical shape - a scenario that continues in a periodic manner as the nano-fiber grows. A closer inspection of the atomic-resolved images reveals that mono-atomic 
steps at the Ni surface play a key role in the nucleation and growth of graphene sheets. The Ni step edges are induced spontaneously in the course of the reaction, even at the graphene-Ni interface (Figure $5 b-g$ ). An additional graphene layer appears in between the pair of such step edges, and the layer grows as the $\mathrm{Ni}$ steps move concurrently towards the ends of the $\mathrm{Ni}$ cluster and vanishes. Clearly, this process involves transport of $\mathrm{C}$ atoms towards and $\mathrm{Ni}$ atoms away from the graphene-Ni interface. The flux of $\mathrm{Ni}$ atoms is directed towards the free $\mathrm{Ni}$ surface producing the observed elongation. Carbon atoms, resulting from methane decomposition at the free surface, must diffuse to the interface to account for the growth of the graphene layer.

The atomic-level observations can be rationalized in terms of gas-surface interactions studied by DFT calculations ${ }^{[37,43]}$. Figure 4 shows the calculated energy diagram where methane dissociation is facilitated at step edges and that carbon atoms bind stronger to step edges than to facet sites. This suggests that the step sites act as the preferential nucleation sites for graphene. The extra binding energy of carbon to a step site turns out to be larger than the energy cost for step formation explaining why steps form spontaneously at the Ni surface ${ }^{[35-37]}$. Moreover, the carbon atoms are more stable in a graphene layer than at a step site showing that there is an energetic driving force for graphene growth. Furthermore, the interplay between the in situ observations and calculated atomic-scale processes ${ }^{[38,44]}$ established a growth mechanism based on surface transport processes with a maximum activation energy barrier of ca. $1.6 \mathrm{eV}$. This is in reasonable agreement with the measured activation barrier for carbon nano-fiber growth in the range $1.3-1.5 \mathrm{eV}^{[35,43]}$, suggesting that transport of carbon atoms confined to the nickel surface could be the rate-limiting step for nano-fiber growth. It has been suggested that carbon transport could also proceed through the bulk Ni nanoparticle ${ }^{[38 \text {, }}$ 45, 46]. Although such an effect may contribute under some reaction conditions, the in situ observations and atomic-scale modelling shows that this is not necessary to obtain a consistent model ${ }^{[37,43,47]}$ and that such a transport path is in fact further activated by ca. $1 \mathrm{eV}$.

Furthermore, the in situ microscopy observations and DFT calculations demonstrate that surface step sites play an important role as centers for graphene growth, mainly because carbon binds more strongly to step sites than to sites at the closed-packed facets on $\mathrm{Ni}$. The findings allow a more general understanding of the effect of many different promoters in Ni-based steam-reforming catalysts to be developed: by (partly) blocking the highly reactive step sites the graphite formation can be suppressed. The blocking of 
the step sites can be achieved by addition of e.g. $\mathrm{K}^{[35]}, \mathrm{S}^{[35,48]}, \mathrm{Au}{ }^{[35,36,49]}$ or $\mathrm{Ag}{ }^{[50]}$ promoter atoms (Figure 6). It turns out that it is energetically favorable for these promoters to adsorb at low-coordinated step sites at the Ni surface. The promotion by these additives reduces the activity for the steam-reforming reaction as was shown by the diminishing of the sticking probability of methane in the presence of potassium on low-index $\mathrm{Ni}(100)$ and $\mathrm{Ni}(111)$ surfaces ${ }^{[51]}$. However, these additives reduce the potential for the formation of graphite even more ${ }^{[35]}$ and can thus be used to design a catalyst with optimum properties to inhibit graphite formation. Recently, the surface dband centre was used as a unified descriptor to determine trends in transition state energies for stepped, planar, and strained Ni surfaces both with and without poisons, promoters and surface alloys ${ }^{[52]}$.

Another significant deactivation mechanism of Ni-based steam-reforming catalysts is the sintering of the $\mathrm{Ni}$ nano-particles during the steam-reforming reaction. The $\mathrm{Ni}$ particles may grow with time, driven by the reduction of the total surface free energy, and thus result in a loss of active surface area. Sintering processes are not easy to describe as they depend on multiple parameters such as temperature, the gas composition, catalyst structure and composition, initial particle size and the support composition and morphology ${ }^{[53]}$. The two main mechanisms that describe sintering are Ostwald ripening (atomic migration) and the particle migration and coalescence mechanism. The sintering mechanism might change with temperature e.g. from a lowtemperature particle coalescence mechanism to a high-temperature atomic migration mechanism and is in general not easy to determine only from the shape of a $\mathrm{Ni}$ particle size distribution ${ }^{[54]}$. By assuming spherical Ni particles, a log-normal metal particlesize distribution, and a particle migration and coalescence mechanism, a model was proposed to predict the $\mathrm{Ni}$ surface area of steam-reforming catalysts as a function of $\mathrm{Ni}$ loading, carrier surface area, temperature, and time ${ }^{[55]}$. Also the influence of the partial pressures of steam and hydrogen on the sintering rate of $\mathrm{Ni}$ particles can be incorporated. From DFT calculations, it was concluded that the formation of $\mathrm{Ni}_{2}-\mathrm{OH}$ species at the surface increases the sintering rate in the presence of steam ${ }^{[56]}$.

\section{Sulfide catalysts}

In situ studies have also played an important role in revealing the nano-scale structures responsible for the promotion of the catalytic activity of hydrotreating $\mathrm{CoMo}-\mathrm{Al}_{2} \mathrm{O}_{3}$ and 
$\mathrm{NiMo}-\mathrm{Al}_{2} \mathrm{O}_{3}$ catalysts in industrial refineries. They were identified as so-called $\mathrm{Co}(\mathrm{Ni})-$ Mo-S structures ${ }^{[57-60]}$. The building blocks of $\mathrm{Co}(\mathrm{Ni})-\mathrm{Mo}-\mathrm{S}$ consist of small $\mathrm{MoS}_{2}$-like domains or nano-crystals. Early structure-activity studies showed that the catalytic activity of these structures is associated with the edges of the highly anisotropic nanocrystals and boosted by presence of $\mathrm{Co}(\mathrm{Ni})$ at these edges. In this respect, it is interesting that the results from techniques such as EXAFS ${ }^{[61-63]}$ suggest that the Co(Ni) atoms are located in the same plane as the Mo atoms, but not at perfect Mo edge sites. The alumina support allows a high dispersion of the $\mathrm{Co}(\mathrm{Ni})-\mathrm{Mo}-\mathrm{S}$ structures and the structures may in fact be present as single $\mathrm{MoS}_{2}$ layers ${ }^{[64,65]}$. The early studies ${ }^{[57,58]}$ also showed that some of the promoter atoms may be present in the support or as separate promoter sulfide structures. These structures are, however, not catalytically significant, and it is therefore important to control the preparation and activation parameters in such a way that their formation is avoided.

In the early in situ studies of the $\mathrm{Co}(\mathrm{Ni})-\mathrm{Mo}-\mathrm{S}$ structures, there was no direct observation of the $\mathrm{MoS}_{2}$ structures and it was typically assumed that the edge structures of $\mathrm{MoS}_{2}$ were similar to those expected from cleaving a bulk $\mathrm{MoS}_{2}$ crystal, i.e. a Mo(10-10) and S(-1010)-edge (Figure 7). For many years it was difficult to test this assumption, but after the introduction of DFT studies [66, 67] and in situ Scanning Transmission Microscopy (STM) ${ }^{[68]}$ it has been possible to observe the nanostructures directly and reveal how the important edges differ dramatically from an expected bulk structure. The studies furthermore showed that the edges of $\mathrm{MoS}_{2}$ and Co-Mo-S structures may not remain static but undergo significant reconstructions depending on the gas phase composition. Direct atom-resolved images of $\mathrm{MoS}_{2}$ showing such reconstructions were obtained for the first time by the use of STM [68]. The great advantage of the STM technique is that the catalytically active edges can be directly imaged at the atomic-scale. Nevertheless, it must be realized that the conditions of the in situ STM experiments are typically very different regarding pressure and temperature from those encountered in industry or in other in situ or operando experiments. However, based on the new insight, the DFT calculations have provided ${ }^{[69]}$ one is now able to predict how structures may change with changes in the composition of the gas [67, 70-72]. The combined STM-DFT studies have also provided important information on the electronic structure of the nano-crystals, which plays a key role in the catalysis. Figure 8 shows that the small sulfide nano-crystals may have unique sites at the edges 
with a metallic-like character ${ }^{[68,73]}$. They were termed the brim sites. These spatially localized brim sites differ from the semi-conducting character of the bulk $\mathrm{MoS}_{2}$ sites and appear due to the crystal truncation. DFT calculations have allowed to understand their origin. The in situ STM investigations also provide detailed insight into the location of the Co and Ni promoter atoms in the Co-Mo-S and Ni-Mo-S structures. The results confirm many of the earlier proposals regarding the location of the promoter atoms but the results also provide a wealth of new insight. For example, it was found that the promoter atoms prefer to be located at specific types of edge sites (the so-called $\mathrm{S}$ edges) and it has also been found that Co-Mo-S and Ni-Mo-S may be present in different modifications ${ }^{[74,75]}$.

Recently, it was found that the metallic-like brim sites are important for the HDS reactivity. For example, in situ STM studies could directly observe reaction intermediates associated with the brim sites (Figure 8). Combined STM and DFT studies ${ }^{[76]}$ have recently shown that the brim sites due to their metallic character may bind sulfur-containing reactants such as thiophene test molecules. Furthermore, when hydrogen is available at the neighboring edge sites in the form of SH-groups, hydrogen transfer reactions may take place resulting in hydrogenation of $\mathrm{C}-\mathrm{C}$ double bonds and breakage of C-S bonds in hydrogenated species. The observation that the brim sites play a key role in the catalysis is novel, since sulfur vacancies were previously assumed to be the active sites ${ }^{[57]}$. In fact, this insight was important in the development of a new generation of improved catalysts for the production of clean fuels. The in situ studies of adsorbed intermediates open vast perspectives for new types of in situ studies giving important insight into the reactions and inhibitions occurring in catalysis. Again, in such studies it may be gainful to combine the STM investigations with other in situ investigations and DFT studies as it needs to be kept in mind that the conditions for the STM studies (both with respect to the substrate and the gaseous surrounding) are far away from realistic reactions conditions

\section{Summary and Conclusions}

The interplay between the combination of results from many in situ and operando experimental techniques and theoretical descriptions down to the atomic level provides great opportunities for establishing a detailed understanding of the structure and operation of many nano-particle catalysts. In fact the adsorption, reaction and kinetics can today in some cases be described down to atomic detail. The development of new in 
situ experimental techniques, including particularly TEM, XRD, XAFS, ASAXS, FTIR, and Raman as well as the development of efficient DFT codes, has been of key importance for elucidating the role of gas-surface interactions on the state of the nanoparticles. Such studies have the advantage that they may even be used directly in an operando-type manner under industrial type conditions. Despite progress of such methodologies for directly correlating catalyst structure and activity by spatial-averaged information, it still seems as a daunting challenge to probe the structure-activity relationship at the individual sites on nano-particle catalysts in their working state. Surface science type techniques, like STM, working with idealized model systems can serve here as a gainful complementary approach. In this case, the theoretical understanding can guide us bridge the information to the industrial operating conditions. The article also illustrates how the improved understanding of the atomic-scale processes at the surfaces of nano-particle catalysts can result in a more rational design of catalysts.

\section{Acknowledgements}

CTCI foundation is acknowledged for the participation in the establishing of the ETEM facility. 


\section{Figures}
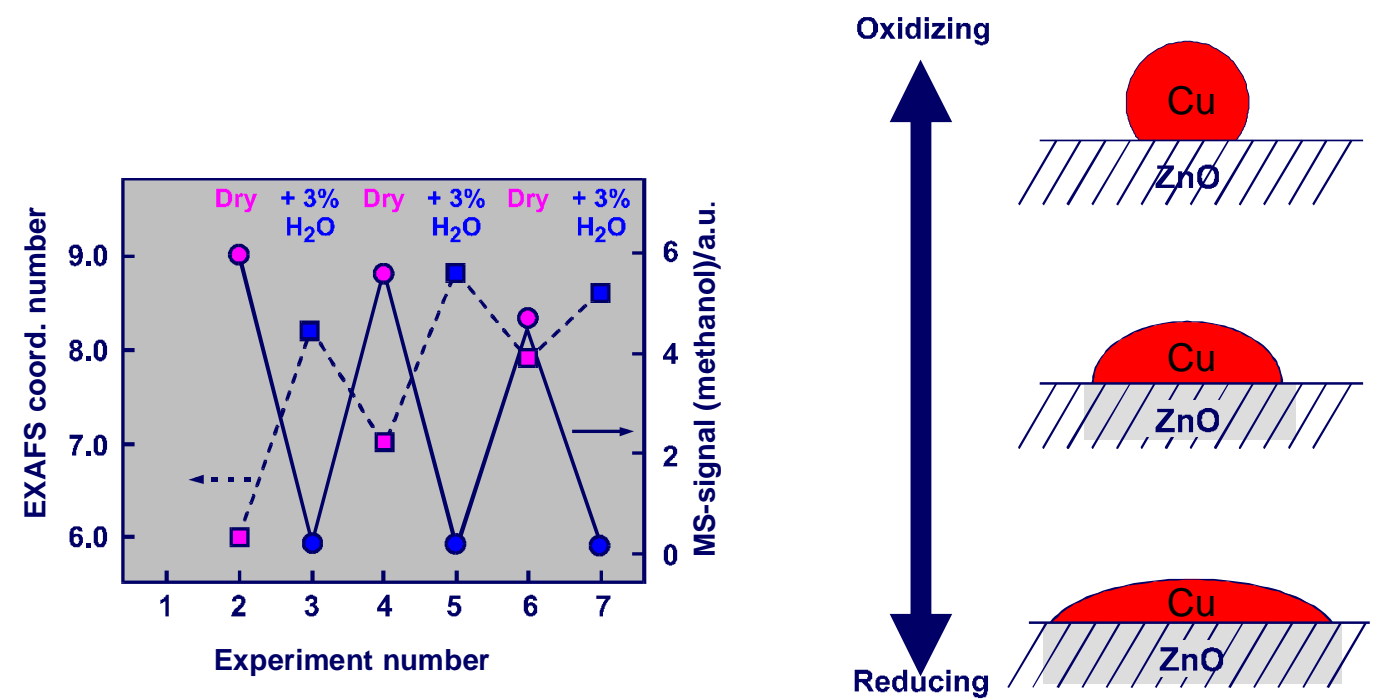

Figure 1

Left: Change of the $\mathrm{Cu}-\mathrm{Cu}$ coordination number as determined by XAFS of a $\mathrm{Cu} / \mathrm{ZnO}$ catalyst upon change of the oxidation potential of the synthesis gas mixture ${ }^{[17,18]}$. Right: Model of the (de-)wetting of $\mathrm{Cu}$ nano-particles on the $\mathrm{ZnO}$ support under reducing (oxidizing) conditions. 


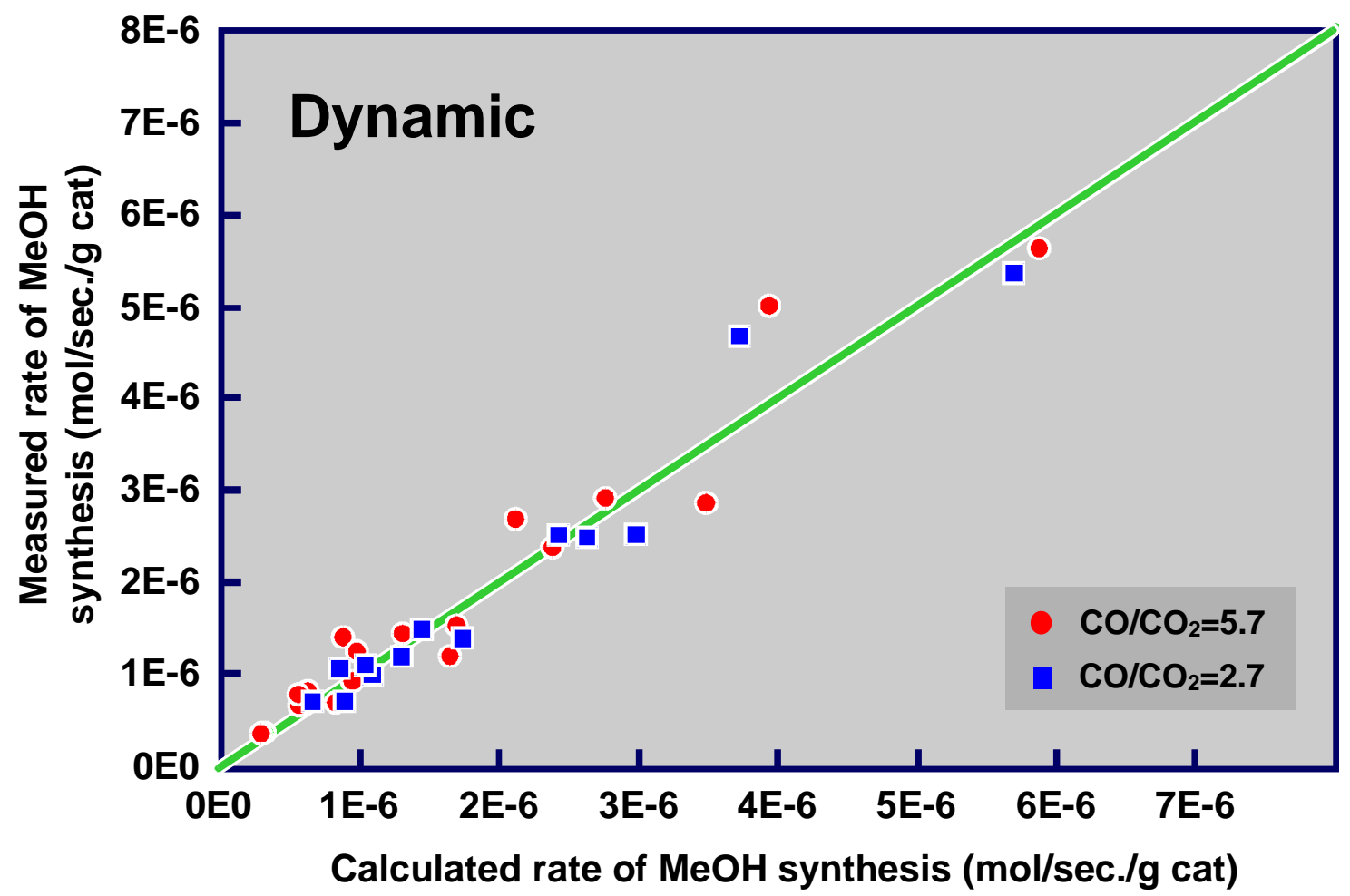

Figure 2

The "dynamic micro-kinetic model" ${ }^{[24]}$ (calculated rate of $\mathrm{MeOH}$ synthesis) is able to explain the measured methanol synthesis reaction rate under different industrial conditions well, whereas a model based on a static morphology of the $\mathrm{Cu}$ nano-crystals results in a significant scattering of the one-to-one correspondence. 

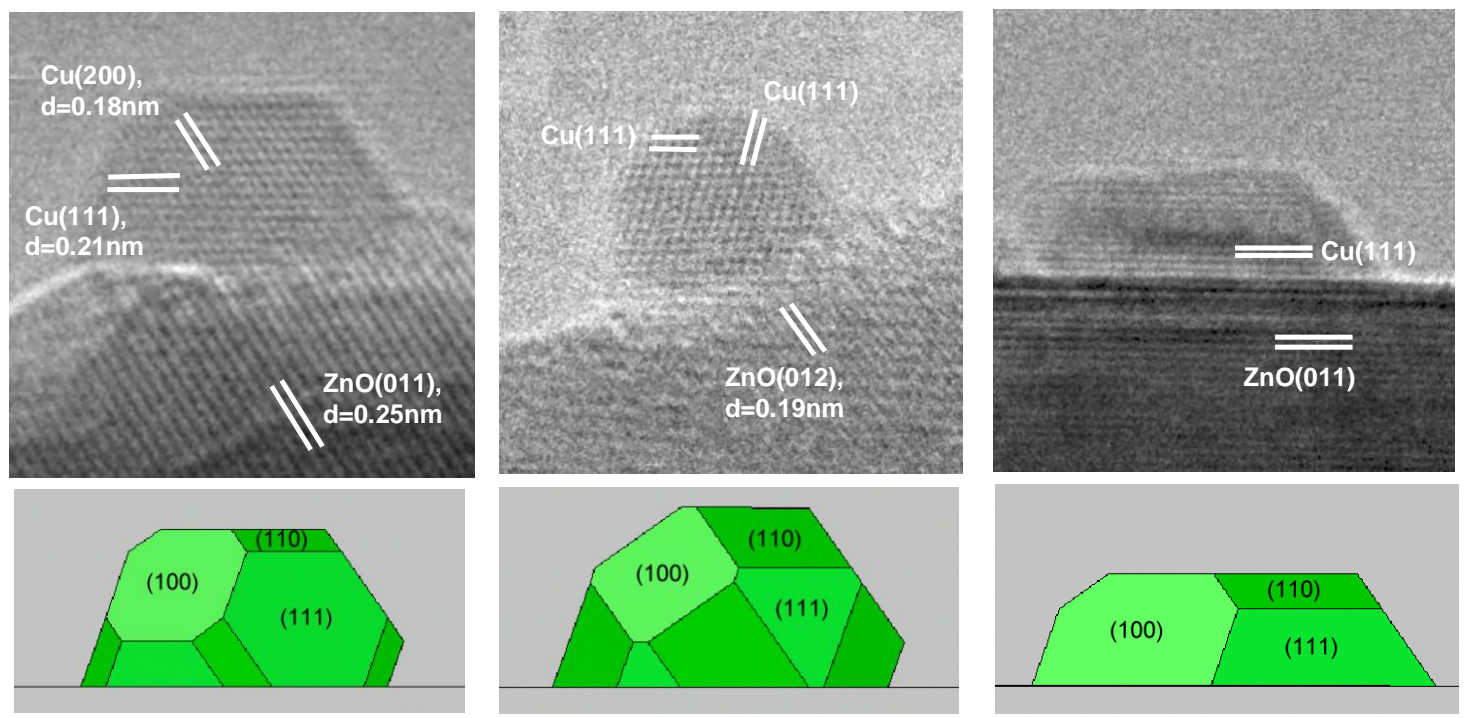

Figure 3

Atomic-resolved ETEM images of individual $\mathrm{Cu} / \mathrm{ZnO}$ nano-crystals under various gas conditions (upper panels) and corresponding Wulff constructions (lower panels). Left: $\mathrm{P}=1.5 \mathrm{mbar} \mathrm{H}_{2}$ at $220^{\circ} \mathrm{C}$; Middle: $\mathrm{P}=1.5 \mathrm{mbar}, \mathrm{H}_{2} / \mathrm{H}_{2} \mathrm{O}=3: 1$ at $220^{\circ} \mathrm{C}$; Right $\mathrm{P}=1.5$ mbar, $\mathrm{H}_{2} / \mathrm{CO}=19: 1$ at $220^{\circ} \mathrm{C}$. From ${ }^{[28]}$. 


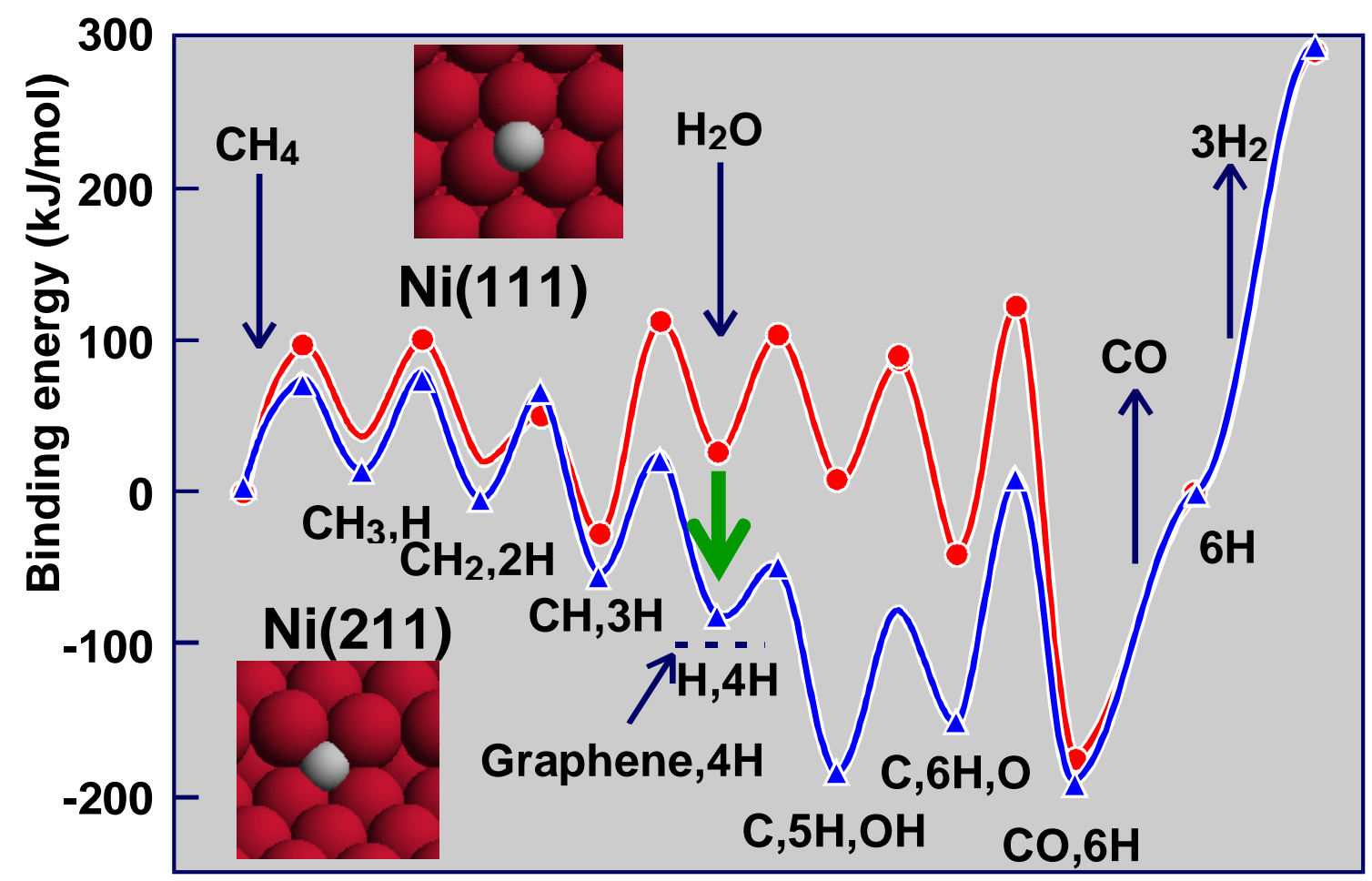

Figure 4

Binding energies for the species on $\mathrm{Ni}(211)$ and $\mathrm{Ni}(111)$ as determined by DFT. All energies are relative to $\mathrm{CH}_{4}$ and $\mathrm{H}_{2} \mathrm{O}$ in the gas phase and calculated using the results for the individual species. Adapted from ${ }^{[35-37]}$. 

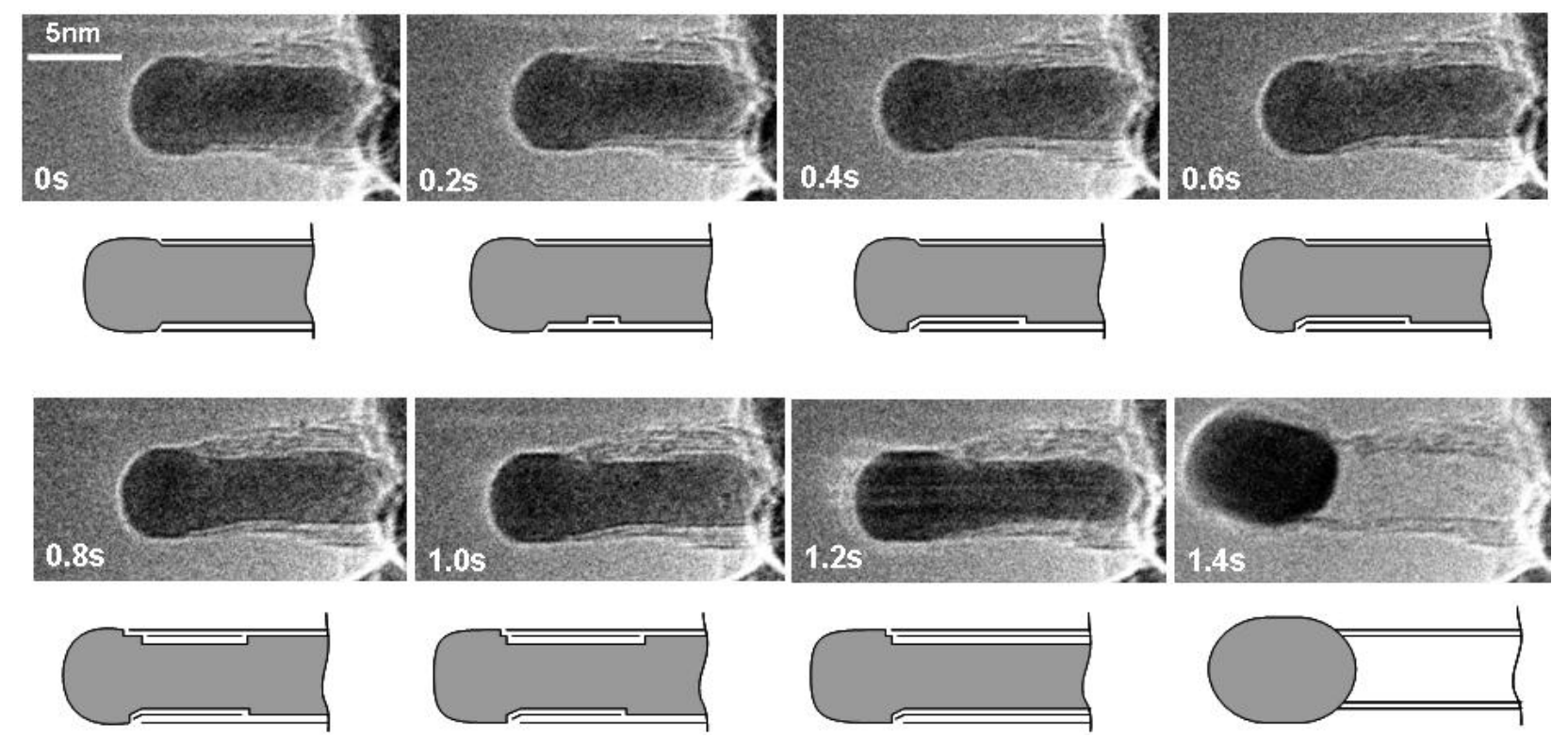

\section{Figure 5}

Image sequence of a growing carbon nano-fibre. Images $\mathrm{a}-\mathrm{h}$ illustrate the elongation/contraction process. Drawings are included to guide the eye in locating the positions of mono-atomic Ni step edges at the $\mathrm{C}-\mathrm{Ni}$ interface. The images are acquired in situ with $\mathrm{CH}_{4}: \mathrm{H}_{2}=1: 1$ at a total pressure of 2.1 mbar with the sample heated to $536^{\circ} \mathrm{C}$. All images are obtained with a rate of 2 frames s$^{-1}$. Scale bar, $5 \mathrm{~nm}$. From ${ }^{[37]}$. 

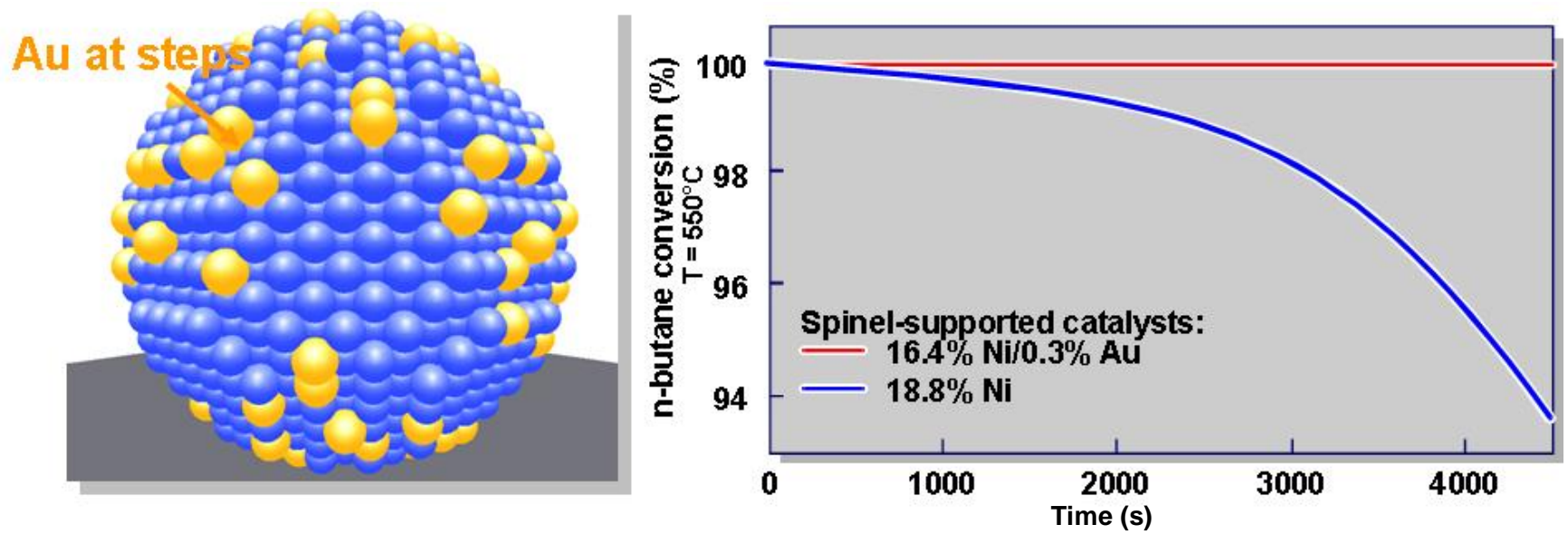

\section{Figure 6}

Left: Model of a Ni-Au surface alloyed nano-particle obtained from effective-medium theory simulations. From ${ }^{[36]}$.

Right: Deactivation of a spinel supported Ni nano-particle catalyst during n-butane conversion (blue trace) and a nearly constant activity of a Au-promoted Ni catalyst (red trace). From ${ }^{[49]}$. 


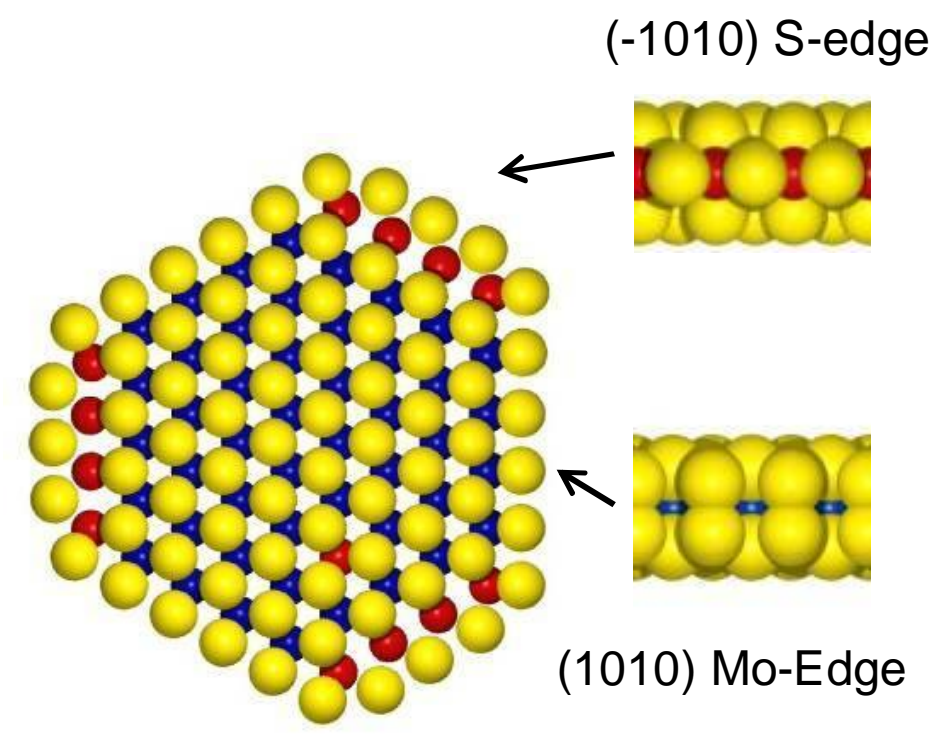

Figure 7

Structural model of a single-layer Co-promoted $\mathrm{MoS}_{2}$ nanocrystal, the Co(Ni)-Mo-S structure showing a top view (left) and side views (right) from the S(-1010)- and the Mo(10-10)-edge terminations. Sulfur atom positions are denoted by yellow spheres, Molybdenum atoms by blue spheres and Cobalt by red spheres. From ${ }^{[69]}$. 
(a)

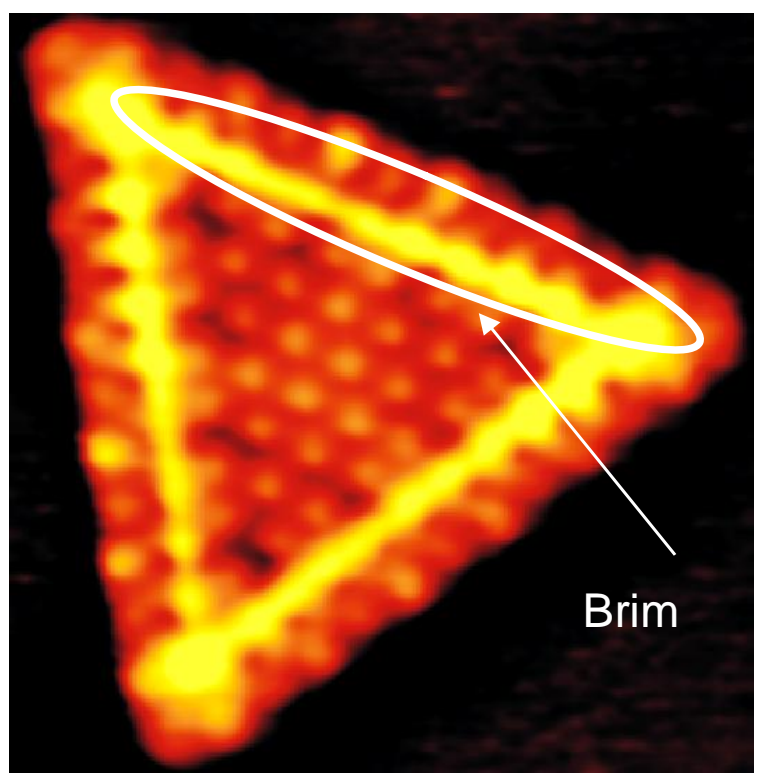

(b)
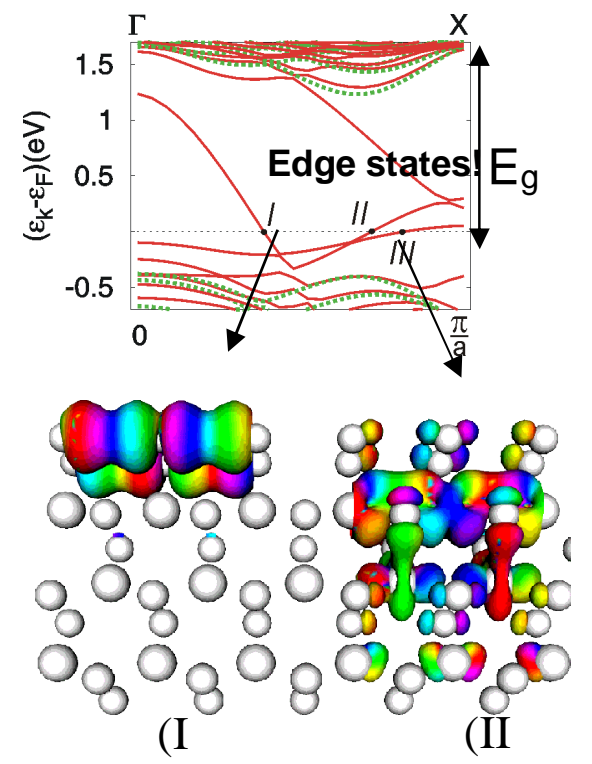

Figure 8

(a) STM image of a single-layer $\mathrm{MoS}_{2}$ nano-crystal containing sites with metallic-like character, the so-called brim sites at the Mo-edge termination. From ${ }^{[68]}$.

(b) Electronic energy bands around the Fermi level for a $\mathrm{MoS}_{2}$ slab (above) and contours of the wave-function corresponding to the metallic states at the Mo-edge (below). From ${ }^{[73]}$. 
Reference List

[1] H. Topsøe, Journal of Catalysis 2003, 216(1-2), 155-164.

[2] Handbook of Heterogeneous Catalysis, (Eds.: G. Ertl, H. Knözinger, and J. Weitkamp), Weinheim, VCH, 1997.

[3] J. W. Niemantsverdriet, Spectroscopy in Catalysis, Weinheim, WileyVCH, 2000.

[4] R. Prins, D. C. Koningsberger, X-ray Absorption: Principles, Applications, Techniques of EXAFS, SEXAFS, and XANES, (Eds.: D. C. Koningsberger and R. Prins), New York, Wiley, 1998, p. 321.

[5] J. M. Thomas, G. A. Somorjai, Topics Catal. 1999, 8(1-2).

[6] B. M. Weckhuysen, Chem. Commun. 2002, 97-110.

[7] In-Situ Spectroscopy in Heterogeneous Catalysis, (Ed.: J. F. Haw), Weinheim, Wiley-VCH, 2002.

[8] J. V. Lauritsen, F. Besenbacher, Adv. Catal. 2006, 50, 97-147.

[9] B. Hammer, J. K. Nørskov, Theoretical surface science and catalysis-calculations and concepts, In: (Ed.: C. G. a. H. Bruce), Advances in Catalysis Impact of Surface Science on Catalysis, Academic Press, 2000, pp. 71-129.

[10] N.-Y. Topsøe, H. Topsøe, Journal of Molecular Catalysis A: Chemical 1999, 141(1-3), 95-105.

[11] M. M. Günther, T. Ressler, B. Bems, C. Büscher, T. Genger, O. Hinrichsen, R. Schlögl, Catalysis Letters 2001, 71, 37.

[12] I. Kasatkin, P. Kurr, B. Kniep, A. Trunschke, R. Schlögl, Angew. Chem. Int. Ed. 2007, 46, 7324.

[13] M. M. Viitanen, W. P. A. Jansen, R. G. v.Welzenis, H. H. Brongersma, D. S. Brands, E. K. Poels, A. Bliek, J. Phys. Chem. B 1999, 103, 6025-6029.

[14] T. Fujitani, J. Nakamura, Applied Catalysis A: General 2000, 191(1-2), 111-129.

[15] T. Fujitani, J. Nakamura, Catalysis Letters 1988, 56, 119-124.

[16] R. N. d'Alnoncourt, M. Kurtz, H. Wilmer, E. Leffler, V. Hagen, J. Shen, M. Muhler, Journal of Catalysis 2003, 220, 249-253.

[17] B. S. Clausen, J. Schiøtz, L. Gråbæk, C. V. Ovesen, K. W. Jacobsen, J. K. Nørskov, H. Topsøe, Topics in Catalysis 1994, 1(3 - 4), 367-376.

[18] J.-D. Grunwaldt, A. M. Molenbroek, N.-Y. Topsøe, H. Topsøe, B. S. Clausen, Journal of Catalysis 2000, 194(2), 452-460.

[19] J. W. Andreasen, F. B. Rasmussen, S. Helveg, A. M. Molenbroek, K. Ståhl, M. M. Nielsen, R. Feidenhans'1, J. Appl. Cryst. 2006, 39, 209.

[20] J. W. Andreasen, O. Rasmussen, R. Feidenhans'l, F. B. Rasmussen, R. Christensen, A. M. Molenbroek, G. Goerigk, J. Appl. Cryst. 2003, 36, 812813.

[21] J. Als-Nielsen, G. Grubel, B. S. Clausen, Nuclear Instruments and Methods in Physics Research Section B: Beam Interactions with Materials and Atoms 1995, 97(1-4), 522-525. 
[23] B. S. Clausen, L. Gråbæk, H. Topsøe, L. B. Hansen, P. Stoltze, J. K. Nørskov, O. H. Nielsen, Journal of Catalysis 1993, 141(2), 368-379.

[24] C. V. Ovesen, B. S. Clausen, J. Schiotz, P. Stoltze, H. Topsøe, J. K. Nørskov, Journal of Catalysis 1997, 168(2), 133-142.

[25] C. V. Ovesen, B. S. Clausen, B. S. Hammershoi, G. Steffensen, T. Askgaard, I. Chorkendorff, J. K. Nørskov, P. B. Rasmussen, P. Stoltze, P. Taylor, Journal of Catalysis 1996, 158(1), 170-180.

[26] M. Muhler, F. Rosowski, G. Ertl, Catalysis Letters 1994, 24(3 - 4), 317331.

[27] P. C. K. Vesborg, I. Chorkendorff, I. Knudsen, O. Balmes, J. Nerlov, A. M. Molenbroek, B. S. Clausen, S. Helveg, Journal of Catalysis 2009, In Press.

[28] P. L. Hansen, J. B. Wagner, S. Helveg, J. R. Rostrup-Nielsen, B. S. Clausen, H. Topsoe, Science 2002, 295(5562), 2053-2055.

[29] J. F. Creemer, S. Helveg, G. H. Hoveling, S. Ullmann, A. M. Molenbroek, P. M. Sarro, H. W. Zandbergen, Ultramicroscopy 2008, 108(9), 993-998.

[30] J. B. Wagner, P. L. Hansen, A. M. Molenbroek, H. Topsøe, B. S. Clausen, S. Helveg, J. Phys. Chem. B 2003, 107, 7753-7758.

[31] N.-Y. Topsøe, H. Topsøe, Topics in Catalysis 1999, 8(3 - 4), 267-270.

[32] M. M. Günther, T. Ressler, R. E. Jentoft, B. Bems, Journal of Catalysis 2001, 203, 133.

[33] J. R. Rostrup-Nielsen, J. Sehested, J. K. Nørskov, Hydrogen and synthesis gas by steam- and $\mathrm{CO}_{2}$ reforming, In: Advances in Catalysis, Academic Press, 2002, pp. 65-139.

[34] J. Wei, E. Iglesia, Journal of Ca 2004, 224, 370.

[35] H. S. Bengaard, J. K. Nørskov, J. Sehested, B. S. Clausen, L. P. Nielsen, A. M. Molenbroek, J. R. Rostrup-Nielsen, Journal of Catalysis 2002, 209(2), 365-384.

[36] A. M. Molenbroek, J. K. Nørskov, B. S. Clausen, J. Phys. Chem. B 2001, 105(23), 5450-5458.

[37] S. Helveg, C. Lopez-Cartes, J. Sehested, P. L. Hansen, B. S. Clausen, J. R. Rostrup-Nielsen, F. Abild-Pedersen, J. K. Nørskov, Nature 2004, 427, 426429.

[38] R. T. K. Baker, M. A. Barber, F. S. Feates, R. J. Waite, Journal of Catalysis 1972, 26, 51.

[39] R. Sharma, Z. Iqbal, Applied Physics Letters 2004, 84, 990.

[40] S. Hofmann, R. Sharma, C. Ducati, G. Du, C. Mattevi, C. Cepek, M. Cantoro, S. Pisana, A. Parvez, F. Cervantes-Sodi, A. C. Ferrari, R. DuninBorkowski, S. Lizzit, L. Petaccia, A. Goldoni, J. Robertson, Nano Letters 2007, 7(3), 602-608.

[41] M. Lin, J. P. Ying Tan, C. Boothroyd, K. P. Loh, E. S. Tok, Y. L. Foo, Nano Letters 2006, 6(3), 449-452.

[42] R. T. K. Baker, P. S. Harris, R. B. Thomas, R. J. Waite, Journal of Catalysis 1973, 30(1), 86-95.

[43] F. Abild-Pedersen, J. K. Nørskov, J. R. Rostrup-Nielsen, J. Sehested, S. Helveg, Phys. Rev. B 2006, 73, 115419.

[44] D. L. Trimm, Catal. Rev. Sci. Eng. 1977, 16, 155. 
[45] J. Rostrup-Nielsen, D. L. Trimm, Journal of Catalysis 1977, 48(1-3), 155-165.

[46] J. A. Rodriguez-Manzo, M. T. H. K. H. W. Terrones, L. Sun, F. Banhart, Nature Nanotechnology 2007, 2, 307-311.

[47] S. Hoffmann, G. F. A. C. Csányi, M. C. Payne, J. Robertson, Phys. Rev. Lett. 2005, 95, 036101.

[48] F. Abild-Pedersen, O. Lytken, J. Engbæk, G. Nielsen, I. Chorkendorff, J. K. Nørskov, Surface Science 2005, 590(2-3), 127-137.

[49] F. Besenbacher, I. Chorkendorff, B. S. Clausen, B. Hammer, A. M. Molenbroek, J. K. Nørskov, I. Stensgaard, Science 1998, 279(5358), 19131915.

[50] R. T. Vang, K. Honkala, S. Dahl, E. K. Vestergaard, J. Schnadt, E. Lægsgaard, B. S. Clausen, J. K. Nørskov, F. Besenbacher, Nature Materials 2005, 4, 160-162.

[51] H. S. Bengaard, I. Alstrup, I. Chorkendorff, S. Ullmann, J. R. RostrupNielsen, J. K. Nørskov, Journal of Catalysis 1999, 187(1), 238-244.

[52] F. Abild-Pedersen, J. Greeley, J. K. Nørskov, Catalysis Letters 2005, 105(1 - 2), 9-13.

[53] J. R. Rostrup-Nielsen, J. Sehested, J. K. Norskov, Hydrogen and synthesis gas by steam- and $\mathrm{C} 02$ reforming, In: Advances in Catalysis, Academic Press, 2002, pp. 65-139.

[54] F. B. Rasmussen, A. M. Molenbroek, B. S. Clausen, R. Feidenhans'1, Journal of Catalysis 2000, 190(1), 205-208.

[55] J. Sehested, Journal of Catalysis 2003, 217(2), 417-426.

[56] J. Sehested, J. A. P. Gelten, I. N. Remediakis, H. Bengaard, J. K. Norskov, Journal of Catalysis 2004, 223(2), 432-443.

[57] H. Topsøe, B. S. Clausen, R. Candia, C. Wivel, S. Morup, Journal of Catalysis 1981, 68(2), 433-452.

[58] C. Wivel, R. Candia, B. S. Clausen, S. Morup, H. Topsoe, Journal of Catalysis 1981, 68(2), 453-463.

[59] B. S. Clausen, H. Topsoe, R. Candia, J. Villadsen, B. Lengeler, J. AlsNielsen, F. Christensen, J. Phys. Chem. 1981, 85(25), 3868-3872.

[60] N.-Y. Topsøe, H. Topsøe, Journal of Catalysis 1983, 84(2), 386-401.

[61] B. S. Clausen, B. Lengeler, R. Candia, J. Als-Nielsen, H. Topsoe, Bull. Soc. Chim. Belg. 1981, 90, 1249.

[62] B. S. Clausen, H. Topsøe, R. Candia, B. Lengeler, In: (Eds.: T. E. White, R. A. Dalla Betta, E. G. Derouane, and R. T. K. Baker), Catalytic Materials, Relationship between Structure and Reactivity, ACS Symposium Series No. 248, 1984, p. 71.

[63] S. N. A. M. Bouwens, D. C. Koningsberger, V. H. J. de Beer, R. Prins, Bull. Soc. Chim. Belg. 1987, 96, 951.

[64] N.-Y. Topsøe, Journal of Catalysis 1980, 64(1), 235-237.

[65] J. Grimblot, P. Dufresne, L. Gengembre, J.-P. Bonelle, Soc. Chim. Belg. 1981, 90, 1311.

[66] L. S. Byskov, J. K. Nørskov, B. S. Clausen, H. Topsøe, Journal of Catalysis 1999, 187(1), 109-122.

[67] H. Schweiger, P. Raybaud, G. Kresse, H. Toulhoat, Journal of Catalysis 2002, 207(1), 76-87. 
[68] S. Helveg, J. V. Lauritsen, E. Lægsgaard, I. Stensgaard, J. K. Nørskov, B. S. Clausen, H. Topsøe, Phys. Rev. Lett. 2000, 84, 951.

[69] J. V. Lauritsen, M. V. Bollinger, E. Lægsgaard, K. W. Jacobsen, J. K. Nørskov, B. S. Clausen, H. Topsøe, F. Besenbacher, Journal of Catalysis 2004, 221(2), 510-522.

[70] J. V. Lauritsen, J. Kibsgaard, G. H. Olesen, P. G. Moses, B. Hinnemann, S. Helveg, J. K. Nørskov, B. S. Clausen, H. Topsøe, E. Lægsgaard, F. Besenbacher, Journal of Catalysis 2007, 249(2), 220-233.

[71] P. G. Moses, B. Hinnemann, H. Topsøe, J. K. Nørskov, Journal of Catalysis 2007, 248(2), 188-203.

[72] H. Topsøe, B. Hinnemann, J. K. Nørskov, J. V. Lauritsen, F. Besenbacher, P. L. Hansen, G. Hytoft, R. G. Egeberg, K. G. Knudsen, Catalysis Today 2005, 107-108, 12-22.

[73] M. Bollinger, J. V. Lauritsen, K. W. Jacobsen, J. K. Nørskov, S. Helveg, F. Besenbacher, Phys. Rev. Lett. 2001, 87, 196803.

[74] J. V. Lauritsen, S. Helveg, E. Lægsgaard, I. Stensgaard, B. S. Clausen, H. Topsøe, F. Besenbacher, Journal of Catalysis 2001, 197(1), 1-5.

[75] J. V. Lauritsen, J. Kibsgaard, G. H. Olesen, P. G. Moses, B. Hinnemann, J. K. Nørskov, B. S. Clausen, H. Topsøe, E. Lægsgaard, F. Besenbacher, Journal of Catalysis 2007, 249, 220-223.

[76] J. V. Lauritsen, M. Nyberg, J. K. Nørskov, B. S. Clausen, H. Topsøe, E. Lægsgaard, F. Besenbacher, Journal of Catalysis 2004, 224(1), 94-106. 